J. Clin. Chem. Clin. Biochem.

Vol. 25,1987 , pp. $855-858$

(C) 1987 Walter de Gruyter \& Co.

Berlin · New York

\title{
Urinary Excretion of $D$-Glucaric Acid in Porphyria Cutanea Tarda
}

\author{
By J. C. Tutor, A. Lopez-Urrutia and M. P. Fernandez \\ Laboratorio Central, Hospital General de Galicia, Clinico Universitario, Santiago de Compostela, Spain
}

(Received May 21/October 5, 1987)

Summary: Twenty patients with porphyria cutanea tarda who had ingested no alcohol for at least 10 days before sampling were found to possess urinary $D$-glucaric acid levels similar to those of 30 clinically healthy controls. Correlation between urinary excretion of $D$-glucaric acid on the one hand and plasma or urinary porphyrin concentrations on the other was not statistically significant. These results suggest that the high urinary concentrations of $D$-glucaric acid found in porphyria cutanea tarda patients by Budillon et al. (Acta Hepato-Gastroenterol. 25 (1978) 267) may have been due to recent consumption of alcohol rather than to the porphyrin pathology.

\section{Introduction}

Porphyria cutanea tarda is due to hypoactivity of hepatic uroporphyrinogen decarboxylase. Two types have been described, sporadic and familial porphyria cutanea tarda $(1,2)$. In the latter, erythrocyte uroporphyrinogen decarboxylase is also hypoactive. The low enzyme activity results in supranormal hepatic accumulation and urinary excretion of porphyrins, particularly the most carboxylated species (uro and heptacarboxyl porphyrins).

The determination of $D$-glucaric acid is frequently used to evaluate hepatic microsomal activity in man $(3,4)$. Budillon et al. (5) have reported increased urinary excretion of $D$-glucaric acid by porphyria cutanea tarda patients, with a highly significant correlation between urinary $D$-glucaric acid and total urinary porphyrin concentrations, and they concluded that in porphyria cutanea tarda there is a close relationship between microsomal function and the porphÿrin metabolic derangement. If correct, these findings suggest that determination of urinary $D$-glucaric acid and other indicators of hèpatic microsomal function could be used for clinical monitoring of porphyria cutanea tarda patients, but as far as we know they have never been verified. In order to check this possibility, we studied urinary excretion of $D$-glucaric acid in porphyria cutanea tarda. Since most porphyria cutanea tarda patients have history of high alcohol consumption, which increases urinary excretion of $D$ glucaric acid $(6,7)$, we avoided interference from this cause by studying patients who had abstained from consuming alcohol for long enough to ensure that it would not affect their urinary $D$-glucaric acid concentrations.

\section{Materials and Methods}

Twenty male porphyria cutanea tarda patients were studied. Fourteen were undergoing treatment consisting in periodic phlebotomy and abstinence from alcohol; four of these cases exhibited clinical and biochemical remission. The remaining six patients had not yet begun phlebotomy treatment, but had abstained from consuming alcohol for at least 10 days before samples were taken for the present study. In a subsidiary study, urine samples were collected from 5 porphyria cutanea tarda patients, whose alcohol consumption had continued at least until 24 hours before sampling. None of the patients was diagnosed as having cirrhosis of the liver or renal dysfunction. Thirty clinically healthy male non-drinkers taking no drugs were used as a control group.

Urine was collected over 24 hours, and $D$-glucaric acid and porphyrin concentrations were determined and related to urine creatinine concentration. Urinary $D$-glucaric acid was determined by the enzymatic method of Simmons et al. (8), and total urinary porphyrins by the spectrophotometric method of $D^{\prime} A$ lessandro-Gandolfo \& Topi (9), using the figures published by Jacobs (10) for the absorptivities of uro- and coproporphyrin in $1.5 \mathrm{~mol} / 1 \mathrm{HCl}$. Uro- and coproporphyrin fractions were determined in accordance with Leahy \& Brien (11). In view of the significant quantities of porphyrinogens excreted by porphyria cutanea tarda patients (12), a portion of each sumple was brought to approximately $\mathrm{pH} 7.5$ with sodium carbonate 
and stored in the dark for 48 hours at $4-8^{\circ} \mathrm{C}$ before analysis; under these conditions the oxidative conversion of the porphyrinogens to the corresponding porphyrins is practically complete (10), while the porphyrins themselves remain stable (13). Urinary creatinine was determined kinetically in a Hitachi 737 analyser using Jaffe's reaction.

Total plasma porphyrin concentrations were determined spectrophotometrically as per D'Alessandro-Gandolfo \& Topi (14), again using the absorptivities reported by Jacobs (10). Given the significant levels of plasma porphyrinogens in patients with porphyria cutanea tarda (15), the method was slightly modified to ensure the conversion of porphyrinogens to the corresponding porphyrins. Samples were at all times protected from light, and analytical procedures were carried out without direct illumination so as to avoid the photodegradation of plasma porphyrins (16). Serum $\gamma$-glutamyltransferase was determined at $37^{\circ} \mathrm{C}$ in a CentrifiChem 600 analyser using $\gamma$-glutamyl-p-nitroanilide as substrate and reagents from Smith Kline Instruments.

The statistical significance of differences between the porphyria cutanea tarda and control groups was estimated using Wilcoxon's test. Correlations were estimated by Pearson's coefficient after normalization of the distributions involved.

\section{Results}

Table 1 lists the results obtained for the controls and porphyria cutanea tarda patients without recent intake of alcohol. There were no statistically significant differences between the urinary $D$-glucaric acid concentrations of these groups, or between those of patients presenting an active pathology with high plasma and urinary porphyrin concentrations and those of patients exhibiting clinical and biochemical remission. In the patients with porphyria cutanea tarda there was no significant correlation between urinary excretion of $D$-glucaric acid on the one hand and either total urinary porphyrins $(\mathrm{r}=0.073)$, uroporphyrin $(r=0.095)$, coproporphyrin $(r=0.080)$, total plasma porphyrins $(\mathrm{r}=0.092)$ or $\gamma$-glutamyltransferase $(r=0.132)$ on the other. No significant correlation was found between serum $\gamma$-glutamyltransferase and plasma or urinary porphyrin concentrations. Urinary excretion of total porphyrins by porphyria cutanea tarda patients was closely correlated with their plasma porphyrin concentrations $(\mathrm{r}=0.966, \mathrm{p}<0.001)$.

In the group of 5 porphyria cutanea tarda patients who had continued drinking, no significant correlation was found between urinary excretion of total porphyrins and $D$-glucaric acid $\left(\dot{r}^{\prime}=0.103\right)$. Their urinary $D$-glucaric acid concentrations ranged from 2.26 to $9.05 \mathrm{mmol} / \mathrm{mol}$ creatinine, with a mean of 5.63 $\mathrm{mmol} / \mathrm{mol}$ creatinine and a median of $6.22 \mathrm{mmol} / \mathrm{mol}$ creatinine. The differences with respect to the control and "abstinent" porphyria cutanea tarda groups are statistically significant $(p<0.01)$, and in 3 of the 5 cases, urinary $D$-glucaric acid excretion exceeded the upper reference limit. The urinary $D$-glucaric acid concentration of a group of non-porphyria cutanea tarda alcoholics, who had recently taken alcohol, was likewise significantly higher $(p<0.001)$ than in the control group (17).

\section{Discussion}

Bacon et al. (18) have recently found in vivo that overloading the liver with iron induces microsomal lipid peroxidation, with a decrease in cytochrome P450 , cytochrome $b_{s}$ and aminopyrine demethylase. It is also well known that a large proportion of porphyria cutanea tarda patients present hepatic siderosis (2, $19,20,21)$ of a severity ranging from slight to levels similar to those found in idiopathic haemochromatosis (2). Blekkenhorst et al. (22) nevertheless found that porphyria cutanea tarda (though not other porphyrias) was associated with hepatic cytochrome P450 levels significantly higher than normal; though paradoxically they were unable to detect the proliferation of the smooth endoplasmic reticulum usually observed during hepatic enzyme induction.

Tab. 1. D-Glucaric acid, total porphyrin and $\gamma$-glutamyltransferase in controls and porphyria cutanea tarda patients without recent intake of alcohol.

\begin{tabular}{|c|c|c|c|c|c|c|c|}
\hline & \multicolumn{3}{|c|}{ Control group } & \multicolumn{3}{|c|}{ Porphyric group } & \multirow[t]{2}{*}{ Significance } \\
\hline & $\mathbf{N}$ & Mean (Range) & Median & $\mathbf{N}$ & Mean (Range) & Median & \\
\hline $\begin{array}{l}D \text {-Glucaric acid } \\
\text { (mmol/mol creatinine) }\end{array}$ & 30 & $1.95(0.98-4.10)$ & 1.84 & 20 & $2.05(0.98-4.69)$ & 1.96 & $p=0.2$ \\
\hline $\begin{array}{l}\text { Urinary porphyrins } \\
\text { ( } \mu \mathrm{mol} / \mathrm{mol} \text { creatinine) }\end{array}$ & 30 & $11.37(2.62-18.58)$ & 12.57 & 20 & $337.71(10.25-81.9 .84)$ & 265.80 & $p<0.001$ \\
\hline $\begin{array}{l}\text { Plasma porphyrins } \\
\text { (nmol/l) }\end{array}$ & - & - & - & 17 & $100.52(10.06-333.10)$ & 46.94 & - \\
\hline $\begin{array}{l}\gamma \text {-Glutamyltransferase } \\
(\mathrm{U} / \mathrm{l})\end{array}$ & 30 & $18.93(7-39)$ & 16.00 & 17 & $63.18(16-220)$ & 42.00 & $\mathrm{p}<0.001$ \\
\hline
\end{tabular}


In man, $D$-glucaric acid is the end product of hepatic glucuronic acid metabolism. Its concentration in urine is increased by the action of microsomal enzymeinducing compounds, and under these conditions urinary $D$-glucaric acid concentrations are significantly correlated with hepatic cytochrome P-450 $(23,24,25)$. As was mentioned above, Budillon et al. (5) reported that in a study of nine porphyria cutanea tarda patients, most of them heavy alcohol consumers, they found above-normal urinary excretion of $D$-glucaric acid and a highly significant correlation between urinary $D$-glucaric acid concentrations and total urinary porphyrin concentrations.

Most male porphyria cutanea tarda patients have a history of heavy alcohol consumption, but it is unlikely that alcohol or alcoholic hepatopathy by themselves can turn secondary coproporphyrinuria into porphyria cutanea tarda (21). Besides triggering agents such as alcohol or oestrogens and the "permissive" role of iron, other aetiological factors must necessarily be involved (2). Induction of hepatic microsomal function by alcohol alters the pharmacokinetics of antipyrine $(26,27)$ and raises the activity of hepatic cytochrome P-450 $(20,26)$ and urinary $D$ glucaric acid $(6,7,28)$. Be that as it may, once ethanol consumption has ceased, the induction effect seems to disappear in a short period of time; the half-life of antipyrine in plasma returns to normal within two weeks (27) and urinary $D$-glucaric acid concentrations within eight days (7), the latter parameter falling most sharply in the first three days of abstinence (17). Clinical and biochemical remission of porphyria cutanea tarda, on the other hand, does not seem to be brought about by abstinence alone (29), and it can apparently be achieved by periodic phlebotomy even when alcohol consumption continues (30), though abstinence may play an important role in maintaining remission (20).

None of the porphyria cutanea tarda patients involved in the first part of the present study had consumed alcohol within the previous 10 days, so that alcohol could have had no effect on their urinary $D$-glucaric acid concentrations. The absence of both urinary $D$ glucaric acid levels greater than those of the controls, and the significant correlation between these levels and plasma or urinary porphyrin concentrations therefore suggests that the results of Budillon et al. (5) may have been due, at least in part, to recent alcohol consumption rather than to the porphyrin pathology. The present results lend no support to the hypothesis that the alterations of porphyrin metabolism in porphyria cutanea tarda are closely related to hepatic microsomal function.

$\gamma$-Glutamyltransferase has been suggested as a useful index of hepatic enzyme induction (4), and in alcoholics with recent consumption of alcohol $(17,28)$ and in male patients treated with antiepileptic drugs (31) it is significantly correlated with urinary excretion of $D$-glucaric acid. The high serum $\gamma$-glutamyltransferase activities frequently observed in porphyria cutanea tarda cases (rarely in other hepatic porphyrias) are possibly due to the enzyme induction by alcohol and/or to liver damage. The patients involved in the present study exhibited no significant correlation between $\gamma$-glutamyltransferase activity and either urinary excretion of $D$-glucaric acid, or plasma or urinary porphyrin concentrations.

Porphyria cutanea tarda is almost always accompanied by some form of hepatopathy, though the latter is usually clinically subdued and moderate as regards its biochemistry, anatomopathology and progression (21). Although liver cirrhosis decreases the urinary excretion of $D$-glucaric acid (32) and the activity of hepatic cytochrome P-450 (33), abovenormal urinary $D$-glucaric acid concentrations have been found in association with different hepatopathies (34), which may explain the increased levels in some patients with porphyria cutanea tarda.

Sweeney (20) has suggested that the ability of certain halogenated aromatic hydrocarbons to cause porphyria in laboratory animals might be due in part to their induction of hepatic microsomal cytochromes, though in porphyrinogenesis iron is likewise clearly involved. The relationship between cytochrome induction and the role of iron in causing uroporphyrinogen decarboxylase deficiency is unknown (20). The urinary $D$ glucaric acid results of the present study do not support the hypothesis that in porphyria cutanea tarda the porphyrin metabolic derangement is correlated with hepatic microsomal function. However, since $D$ glucaric acid excretion represents an indirect parameter of microsomal enzyme induction, other tests such as $6 \beta$-hydroxycortisol which is formed via hepatic cytochrome P-450 might afford helpful data.

\section{Acknowledgement}

The authors wish to thank Dr. M. Taboada of the Hospital General de Galicia's dermatology service for providing clinical data concerning the porphyria cutanea tarda patients studied. 


\section{References}

1. Rimington, C. (1985) Scand. J. Clin. Lab. Invest. 45, 291 301.

2. Hindmarsh, J. T. (1986) Clin. Chem. 32, 1255-1263.

3. Ideo, G., Bellati, G., Bellobuono, A., Mocarelli, P., Marocchia, A. \& Brambilla, P. (1982) Clin. Chim. Acta 120, $273-283$.

4. Goldberg, D. M. (1980) Clin. Chem. 26, 691-699.

5. Budillon, G., Ayala, F., Carrella, M. \& Mazzaca, G. (1978) Acta Hepato-Gastroenterol. 25 267-270.

6. Spencer-Peet, J., Wood, D. C. F., Glat, M. M. \& Wiseman, S. M. (1975) Br. J. Addict. 70, 359-364.

7. Mezey, E. (1976) Res. Commun. Chem. Pathol. Pharmacol. $15,735-742$.

8. Simmons, C. J., Davis, J., Dordoni, B. \& Williams, R. (1974) Clin. Chim. Acta 51, 47-51.

9. D'Alessandro-Gandolfo, L. \& Topi, G. (1973) Clin. Chim. Acta 49, 329-332.

10. Jacobs, S. L. (1974) In: Clinical Chemistry. Principles and Technics, 2nd edn. (Henry, R. J., Cannon, D. C. \& Winkelman, J. W., eds.) pp. 1215-1263, Harper and Row Publishers, Hagerstown.

11. Leahy, D. T. \& Brien, T. G. (1982) J. Clin. Pathol. 35, $1232-1235$

12. Martasek, J., Jirsa, M. \& Kordac, V. (1982) J. Clin. Chem. Clin. Biochem. 20, 113-117.

13. Fernandez-Cano, P. \& Labbe, R. F. (1983) Clin. Chim. Acta 132, 317 320 .

14. D'Alessandro-Gandolfo, L. \& Topi, G. (1976) LAB 3, 445448.

15. Martasek, P., Jirsa, M. \& Kordac, V. (1982) Arch. Dermatol. 118, 624-625.

16. Poh-Fitzpatrick, M. B. \& De Leo, V. A. (1977) J. Invest. Dermatol. 69, 510-512.

17. Tutor, J. C., Alvarez, A., Bernabeu, F., Pardiñas, M. C., Paz, J. M. \& Lareu V. (1988) Clin. Biochem. (in press).
18. Bacon, B. R., Healey, J. F., Brittenham, G. M., Park, C. H., Nunnari, J., Tavill, A. S. \& Bonkovsky, H. L. (1986) Gastroenterology $90,1844-1853$

19. Hindmarsh, J. T. (1983) Clin. Biochem. 16, 209-219.

20. Sweeney, G. D. (1986) Clin. Biochem. 19, 3-15.

21. Enriquez de Salamanca, R., Arnalich, F. \& De Diego, A. (1980) Gastroenterol. Hepatol. 3, 291-302.

22. Blekkenhorst, G., Pimstone, N. R. \& Eales, L. (1976) In: Porphyrins in Human Diseases (Doss, M., ed.) pp. 299311, Karger, Basel.

23. Lecamwasan, D. S. (1975) Br. J. Clin. Pharmacol. 2, $546-$ 548.

24. Sotaniemi, E. A., Pelkonen, R. O. \& Pukka, M. (1980) Eur. J. Clin. Pharmacol. 17, $267-274$.

25. Hunter, J., Maxwell, J. D., Stewart, D. A. \& Willians, R. (1973) Biochem. Pharmacol. 22, 743-747.

26. Luoma, P. V., Sotaniemi, E. A., Pelkonen, R. O. \& Ehnholm, C. (1982) Res. Commun. Chem. Pathol. Pharmacol. $37,91-96$.

27. Cushman, P., Barboriak, J. J., Liao, A. \& Hoffman, N. E. (1982) Life Sci. 30, $1721-1724$.

28. Rosalki, S. B. (1984) In: Clinical Biochemistry of Alcoholism (Rosalki, S. B., ed.) pp. 65-92, Churchill and Livingstone, Edinburgh.

29. Di Padova, C., Marchesi, L., Cainelli, T., Gori, G., Podensani, S. A., Rovagnati, P., Rizzardini, M. \& Cantoni, L. (1983) Am. J. Med. Sci. 285, 2-12.

30. Lundvall, O. (1971) Acta Med. Scand. 189, 33-49.

31. Tutor, J. C., Fernandez, M. P. \& Lopez-Urrutia, A. (1985) Acta Bioquim. Clin. Latinoam. 19, 303-312.

32. Escartin, P., Rossi, I. \& Arenas, I. (1976) Rev. Esp. Enf. Ap. Digest. 47, 329-336.

33. Escartin, P., Rossi, I., Diaz, J. J. \& Gosalves, M. (1976) Rev. Clin. Esp. 142, 309-317.

34. Herzberg, G. M. \& Wiemer, M. H. (1978) Clin. Chem. 24, 1759-1761.
Dr. J. Carlos Tutor

Laboratorio Central

Hospital General de Galicia

E-15705 Santiago de Compostela 